\title{
OPTIMAL MODIFIED COMBINED SYSTEM FOR VIBRATION CONTROL
}

\author{
S. A. HASSAN , E. M. EL-BEHEIRY ${ }^{* *}$, \& S. A. EL-SHAKERY
}

ABS'YRAC'

This paper presents the design considerations and performance capabilities of a modified series combination of passive and actlve elements as a system for vibration control. The investigated primary model consists of a main mass and a randomly excited support. The performance measures, which considered to be minimal, are the main mass acceleration and the relative displacement between the mass and the system support. The operation of the modified system depends essentially on an 1 mplemented 1deal filtration process in the proposed combination. This process is realized in two different ways: (1) by the use of an ldeal low pass filter (LPF), (2) by the use of an ldeal high pass rilter (HPF). Additionally, this process controls the flow of the command signal of the combined system which operates the active element. Thereby, the modified system has the property of operating either as a comblned system or as a classical passive system. The stochastic optimal control theory in addition to a graphical criterion are well posed together in order to determine the effective cut-off frequency for any of the $1 \mathrm{mplemented} \mathrm{ideal} \mathrm{filters.} \mathrm{The} \mathrm{pertinent} \mathrm{results}$ are compared with those of the combined system. In contrast. they are found to be more encouraging, superior, and compatible with the requirements of mary actual engineering applications.

\section{INTRODUCTION}

Basically, the passive vibration isolation systems offer simplicity, reliability, stability, and low cost [1]. In contrast, the rully active systems are costly, complex, and require an external power supply. While, the semi-active systems are significantly simpler and less costly than the fully active ones. The original concept of semi-activity has been presented by Karnopp et al [3]. This concept depends essentially on the 1 mplementation of an active damper such that its associated power is always dissipative. In addition, it requires only slgnal processing and low power supplies. Moreover, the semi-active systems of fer the reliability and cost efrectiveness

* Asst. Prof., * Teah. Asst. *** Assoc. Prof. Prod. Engg.

\& Mech. Des. Depart., Faculty of Engg., Menoufia University Shebin El-Kom, A. R. E. 
'comparable to passive systems enhanced by performance close to 7 that of active ones [4]. Alternative schemes of semi-activity have been presented by Rakheja and Sankar [5], and Al anoly and Sankar [6] for the realization of a more simplified system hardware. The active systems are intended to be used in comblnation with classical passive elements in order to increase their rellability and to reduce, if possible, the supplied power. In such situation, the full performance poteritial of active systems can not be achieved due to the control policy used and the combination suggested $[3,4,7]$. The $r u l l$ performance potential has been proven by Guntur and Sankar [8] for various parallel combinations in case of harmonically excited single-DOF system. In essence, The parallel combination complicates, to a large degree, tunability of the active element for varying operating conditions, since the passive force is always a part of the total control force. While in case of a series combination the active force is independent of values of the passive elements [a].

In this work, a series combination of a one active element and two passive elements (ilnear spring and viscous damper) is considered. Such combination provides the fail-safe feature for vibration control, 1.e., the system works as a passive one in case of fallure of the active element. Moreover, it allows the adaptation of the system for varying operating conditions. On basis of many frequency response predictions, a quite different methodology from that of Karnopp is investigated for the realization of a semi-active vibration control.

\section{MODIFIED COMBINED SYSTEM CONFIGURATION}

The schematic diagram of the modified system is shown in Fig. (1). The system states are measured and combl ned properly by the ald of a signal conditioner and a microcomputer supervisor to perform the electrical signal which equivalent to the desired contral law (force) of the combined system $u_{c}$. This signal is red 1 nto an ldeal filtration process to give the modified combined control law $u_{m}$. Then, the signal $u_{m}$ can be amplified and red into a force generator which generates a force proportional to the controlled state variables. On basis of a prescribed criterion for determining the effective cut-of $f$ frequency, the ideal filtration process determines whether the force generator (actuator) will work or not. In the time where the actuator becomes inactive, it is regarded as a rigid connection between the main mass and the massless plate, and the system seems to be a classical passive single-Dof system. Additionally, the mass of the actuator is neglected in comparison with the main mass of the primary system. But, when the actuator operates $1 t$ is regarded as an ideal force generator, 1.e., no $11 \mathrm{mltat}$ tons to the frequency band or the peak force capability $[5,6,8,9]$, and the system seems to be a combined vibration control system of two-DOF. In practice, the actuator can be realized as a pneumatic servovalve, electrohydrualic servomotor, etc. Also, it is assumed here that the system state variables are all measurable as well as the excitation. 


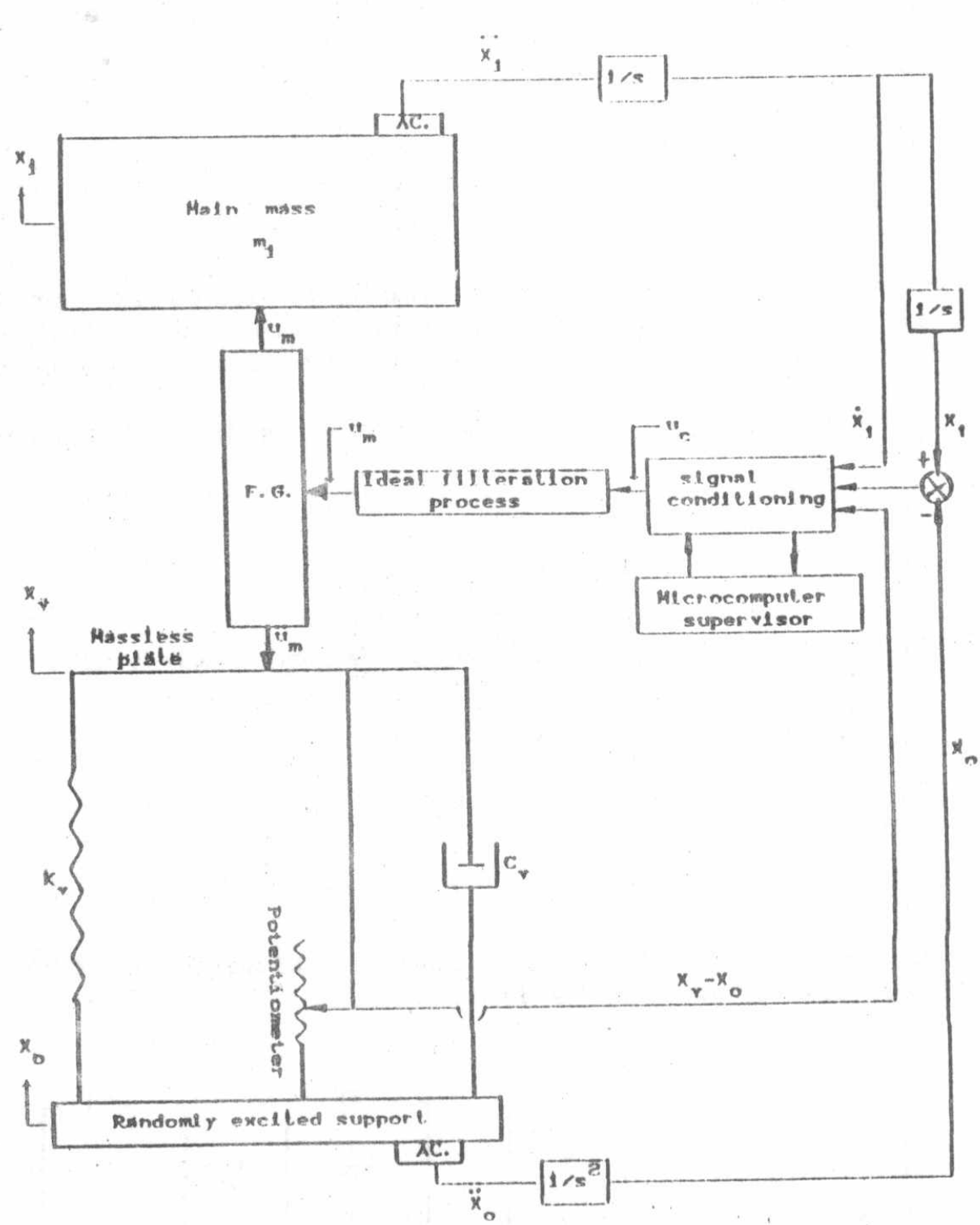

Fig. 1 Scluematic diagram of the modifled coimblined system

\section{SYSTEM ANALYSIS}

A band-1 $1 \mathrm{mited}$ stationary random excitation $x_{0}$ is imparted at the support of the investigated system shown in Fig.1. The power spectral density function of this excitation is $[3,9]$.

$$
S_{0}(\omega)=\frac{V_{0}}{\omega^{2}}=\frac{V_{0}}{-s^{2}}
$$

It is common practice in 1 iterature [9,10] to treat the velocity or such excitation as a white nolse process such that :

$$
\dot{x}_{0}=w(t)
$$


$\Gamma_{A}$ white noise excitations satisfies:

$E[w(t)]=0$

$E[w(t) w(\tau)]=2 \pi V_{0} \delta(t-\tau)$

It is assumed here that $w(t)$ has a Guassian probability distribution ard that Eqn. (3) 1 mplies a zero mean value, while Eqn(4) indicates the independence of the mean square value of $t 1$ me.

From Fig.1 the equations of motion of the modified system are.

$$
\begin{aligned}
& m_{1} \ddot{x}_{1}=u_{m} \\
& k_{v}\left(x_{v}-x_{0}\right)+c_{v}\left(x_{v}-\dot{x}_{0}\right)=-u_{m}
\end{aligned}
$$

And the system state variables are selected such that,

$$
\begin{aligned}
& Y_{1}=X_{1}-X_{0} \\
& Y_{2}=X_{V}-X_{0} \\
& Y_{9}=X_{1}
\end{aligned}
$$

Differentiating these states and substituting Eqns. (2), (5) and (6) to get on the state space form:

$$
\left[\begin{array}{l}
\dot{Y}_{1} \\
\dot{Y}_{2} \\
\dot{Y}_{9}
\end{array}\right]=\left[\begin{array}{ccc}
0 & 0 & 1 \\
0 & -\frac{K_{v}}{C_{v}} & 0 \\
0 & 0 & 0
\end{array}\right]\left[\begin{array}{c}
Y_{1} \\
Y_{2} \\
Y_{g}
\end{array}\right]+\left[\begin{array}{c}
0 \\
-\frac{1}{C_{v}} \\
\frac{1}{m_{1}}
\end{array}\right] u_{m}+\left[\begin{array}{c}
-w(t) \\
0 \\
0
\end{array}\right]
$$

With controlled outputs.

$$
[Z]=\left[\begin{array}{l}
Z \\
Z_{V}
\end{array}\right]=\left[\begin{array}{lll}
1 & 0 & 0 \\
0 & 1 & 0
\end{array}\right]\left[\begin{array}{c}
Y_{1} \\
Y_{2} \\
Y_{3}
\end{array}\right]
$$

The modified control law can be related to the desired combined as follows.

$$
u_{m}=r_{c} u_{c}
$$

where, $u_{c}$ according to the signal processing in Fig. 1 is given by.

$$
u_{c}=G_{1}\left(x_{1}-x_{0}\right)+G_{2}\left(x_{v}-x_{0}\right)+G_{3} \dot{X}_{1}
$$


$r_{\text {and }} \mathrm{f}_{c}$ is a constant determines the operation of the ideall fitration process, and can be defined in case of operation of a LPF as follows.

$$
f_{c}= \begin{cases}1 & \text { if } \omega<\omega_{c} \\ 0 & \text { if } \omega \geq \omega_{c}\end{cases}
$$

While in case of operalion of a HPF it can be defined as :

$$
f_{c}= \begin{cases}1, & \text { if } \omega>\omega_{c} \\ 0 & \text { if } \omega \leq \omega_{c}\end{cases}
$$

Therefore, when $r_{c}$ equals $1 u_{c}$ replaces $u_{m}$ in the second term of Eqn. (7), and the modified system behaves exactly $11 \mathrm{ke}$ a combined system of two-DOF. Conversely, when $f_{c}$ equals $0 u_{m}$ in Eqn. (7) vanishes, and the actuator becomes a rigid connection between the maln mass and the massless plate, and the modified system behaves exactly like a classical passive single-DOF system.

The performance measures elther in case of operation as a combined system or as a passive system can be calculated by substituting Eqns. ( 9$)$ and ( 10$)$ into Eqns. (5) and ( 6$)$ to yield:

$$
\begin{aligned}
& m_{1} \ddot{x}_{1}-r_{c}\left[G_{1}\left(x_{1}-x_{0}\right)+G_{2}\left(x_{v}-x_{0}\right)+G_{3} \dot{x}_{1}\right]=0.0 \\
& k_{v}\left(x_{v}-x_{0}\right)+C_{v}\left(\dot{x}_{v}-\dot{x}_{0}\right)+f_{c}\left[G_{1}\left(x_{1}-x_{0}\right)+G_{2}\left(x_{v}-x_{0}\right)+G_{3} \dot{x}_{1}\right]=0.0
\end{aligned}
$$

Arter performing some algebraic manipulations the set (13) can be rewritten in a complex matrix form as follows.

$$
\begin{aligned}
& {\left[\left[\begin{array}{cc}
-m_{1} \omega^{2}-r_{c} G_{1} & -r_{c} G_{2} \\
r_{c} G_{1} & k_{v}+r_{c} G_{2}
\end{array}\right]+j\left[\begin{array}{cc}
-f_{c} G_{g} \omega & 0 \\
r_{c} G_{3} \omega & c_{v} \omega
\end{array}\right]\left[\begin{array}{l}
x_{1} \\
x_{v}
\end{array}\right]=\right.} \\
& {\left[\left[\begin{array}{c}
-r_{c}\left(G_{1}+G_{2}\right) \\
k_{v} r_{c}\left(G_{q}+G_{2}\right)
\end{array}\right]+j\left[\begin{array}{cc}
0 \\
c_{v} \omega
\end{array}\right]\right] x_{0}}
\end{aligned}
$$

Without loss of generality $x_{0}$ in the last complex matrix equation is equated to unity. Hence, the outcomes of this equation will be :

$\left|x_{1}\right|$ represents the transfer function of the main mass Lidisplacement. 
||$x_{1}-1 \mid$ represents the transfer function of the relative displacement between this mass and the system support.

Since the excitation is a stationary random process, the mean square values of the acceleration and the relative displacement can be conveniently written as [12]:

$$
\begin{aligned}
& E\left[\ddot{x}_{1}^{2}\right]=\int_{\omega_{1}}^{\omega_{u}}\left|x_{1}\right|^{2} \frac{v_{0}}{\omega^{2}} \omega^{4} d \omega . \\
& E\left[z^{2}\right]=\int_{\omega_{1}}^{\omega_{u}}\left|x_{1}-1\right|^{2} \frac{v_{0}}{\omega^{2}} d \omega .
\end{aligned}
$$

\section{OPTIMIZATION PROBLEM}

It should be kept in mind that the optimization problem of the modified system is considered only when it works as a combined system at all times of operation over the specified frequency band. While in the time of operation as a passive system, there is no need for optimizing the passive elements, since their optimality may deteriorate the potency of the filtration process. Thus any set of passive elements by which the maximum exploitation of the filtration process can be achieved is said to be optimum.

The state space form of Eqns. (7) and (8) can be rewritten in a more general form as follows.

$$
\begin{aligned}
& {[\dot{Y}]=[A][Y]+[B][U]+[W]} \\
& {[Z]=[V][Y]}
\end{aligned}
$$

The statement of the regulator problem here is to find out the optimum steady state control law $u_{c}$ that minimizes the following performance 1 ndex :

$$
P . I .=.5 \underset{\substack{\operatorname{Lim} \\ \imath \rightarrow \infty}}{E}\left[[Z]^{T}[Q][Z]+[u]^{T}[R][u]\right]
$$

subject to the system dynamics in the specified state space rorm of Eqns. (15) and (16)

Where, $R=R_{1}, \quad Q=\left[\begin{array}{cc}Q_{1} & 0 \\ 0 & Q_{2}\end{array}\right]$

The interpretation of the P.I. in Eqn. (17) is that the term E[ $Z^{\mathrm{T}}$ Q Z] minimizes the controlled output ( $Z$ and $\left.Z_{v}\right)$, while the term $E\left[u^{T} R\right.$ u minimizes the control law which, in some sense, proportional to the main mass acceleration. The general solution to this problem can be found in Appendix A. For Further detalls about the behaviour of the combined system in comparison with
the fully active system you can see Ref.[2]. 
The numerical calculations are done in the region of $f$ ixed parameters $m_{1}=100 \mathrm{~kg}$. and $v_{0}=.001 \mathrm{~m}^{2}$. s. During the solution of the regulator problem the weighs $R_{1}$ and $Q_{2}$ are equated to the unity, while the weight $Q_{1}$ is varied between $1 \times 10^{\circ}$ to $3 \times 10^{\circ}$ with step equals $1 \times 10^{6}$ to obtain a considerable range of trade-of $f$ solutions. Then Simpson's rule is used for calculating the r.m.s. values of the specified performance measures over a frequency band $r$ anges between $\omega=1$ and $\omega=100 \mathrm{rad}$. $/ \mathrm{s}$. The DIAGONALIZATION method [11] is used to solve matrix Riccati equation (AB)

\section{RESULTS}

In the sense of the resulted set of optimum trade-off solutions, three solutions are selected such that one of them is medium and the two others are extremals. Hence, the frequency response of the combined system at these three solutions are plotted versus that of the passive system. Figs. $2,3,--7$ show many frequency response predictions at various combination of $\xi_{v}$ and $\omega_{v}$. In general, the effort in the present work is posed for treating the problem of determining $\omega_{c}$ of any of the suggested filtration processes in a general sense. In other words, it is very significant from the practical point of view to relate the determination of $\omega_{c}$ to either fixed or variable parameters in the system. of course, this will save, to a considerable extent. many sophisticated frequency response predictions before deciding the efrective value of $\omega_{c}$.

In this manner, the points of intersection between the vertical centre 1 ines and the horizontal axes in Figs. (2-a), (3-a), and (4-a) indicate that $\omega_{0}$ of a LPF can be approximately related to $\omega_{v}$ as rollows.

$$
\omega_{c} \cong \sqrt{2} \omega_{v}
$$

The points of intersection between the centre lines and the horizontal axes in Figs. $(2-b),(3-b)$, and $(4-b)$ indicate that $\omega_{0}$ of a LPF can be related to $\omega_{v}$ by use of the following approximate relation.

$$
\omega_{c} \cong 2.0 \omega_{v}
$$

In Eqn. (19) the articulation 1 s given to $\ddot{x}_{1}$ to have the maximum exploitation in case of using a LPF, while in Eqn.(2O) the articulation 1 s given to $Z$. However, both Eqns. (19) and (20) are not applicable when $\xi$, becomes either moderate or 1 arge. The last cautionary remark can be verifled by predicting the points of intersection between the centre 11 nes and the hor 1 zontal axes L in Figs. 5, 6, and 7 

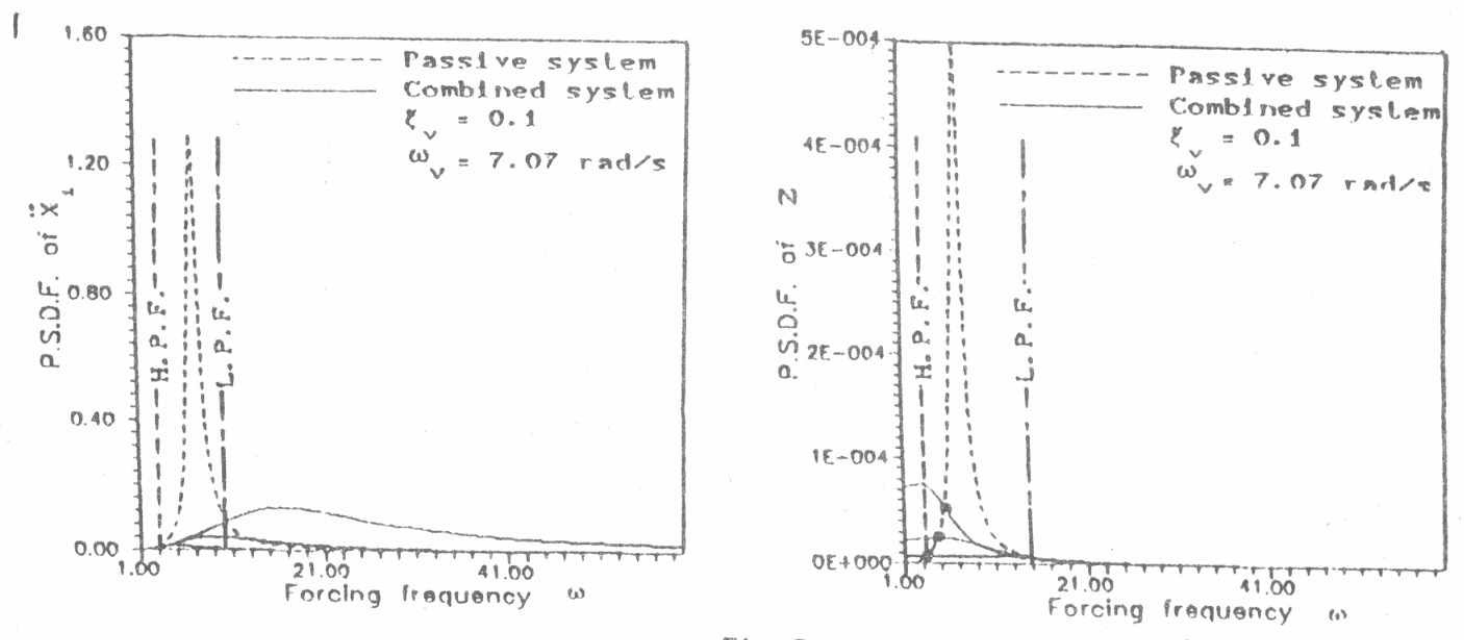

Fig.

$$
\text { -b- }
$$
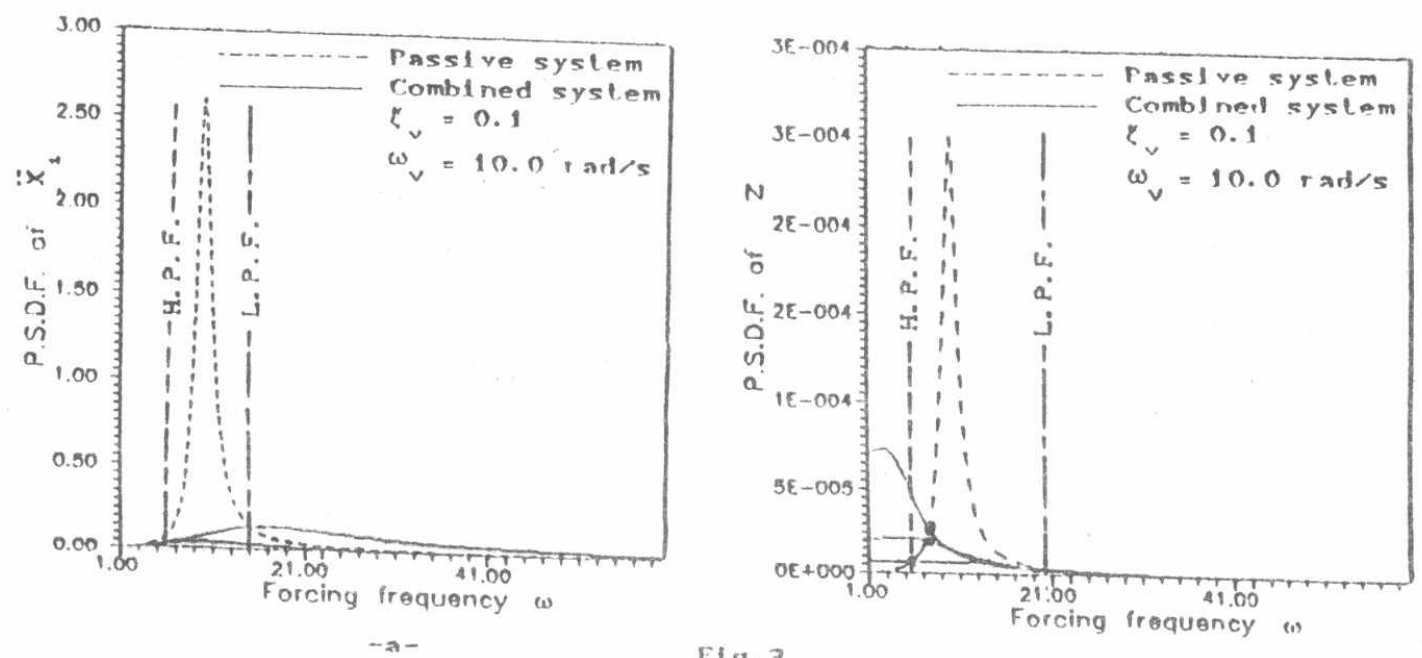

Fig. 3
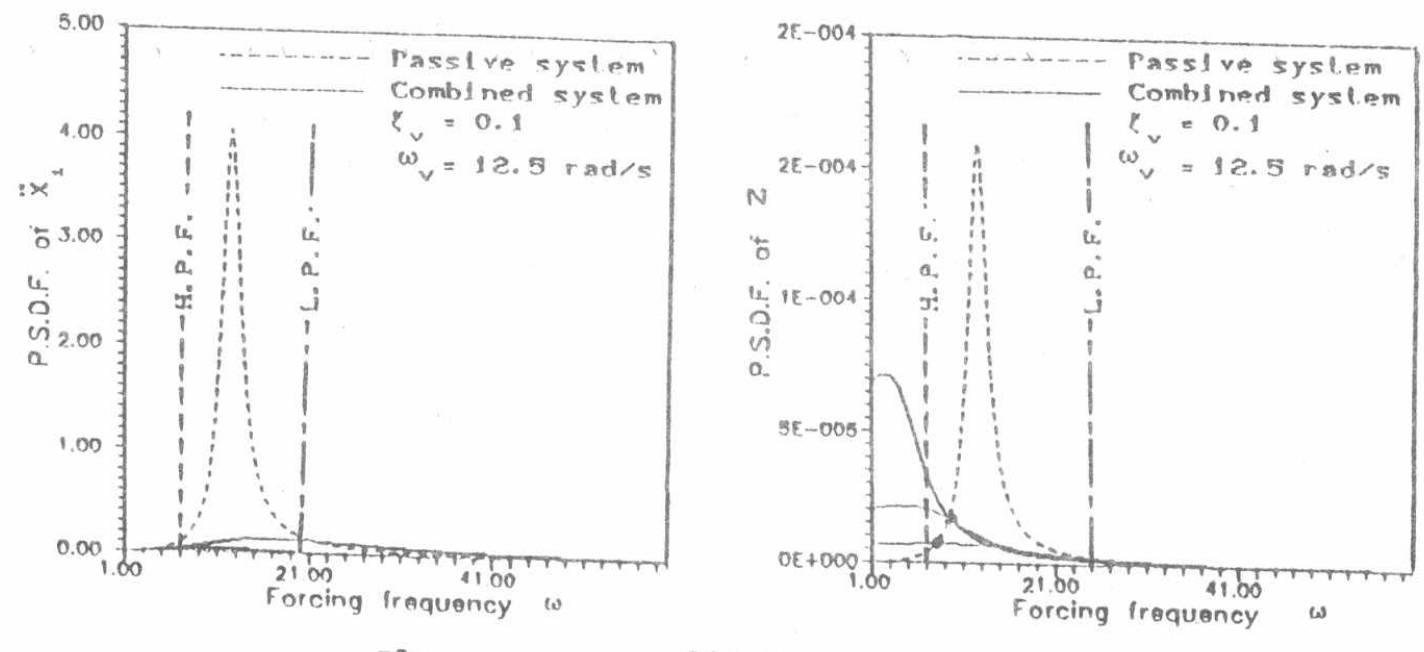

Fig. 4

$-b-$ 
r
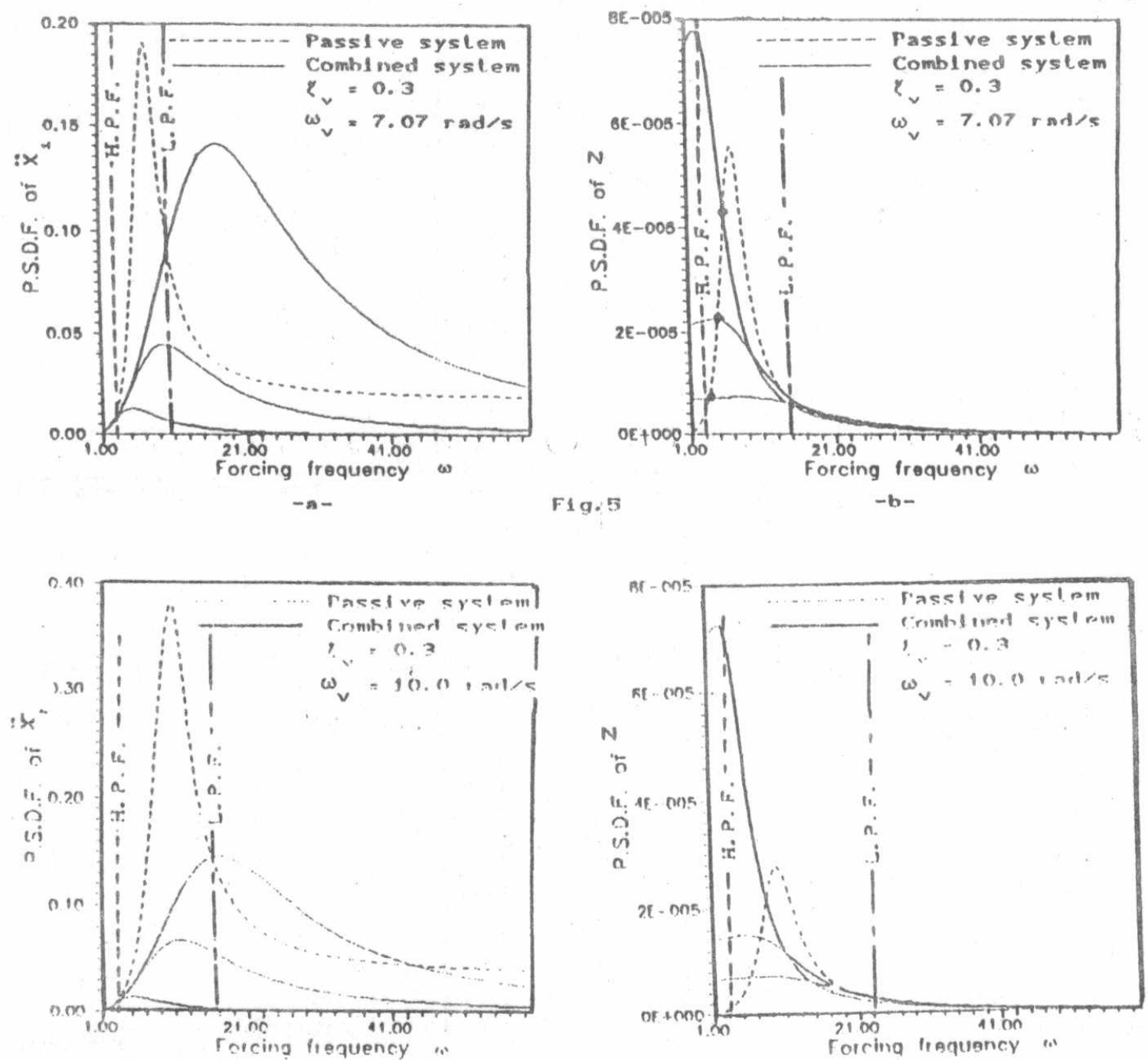

Fig. 6
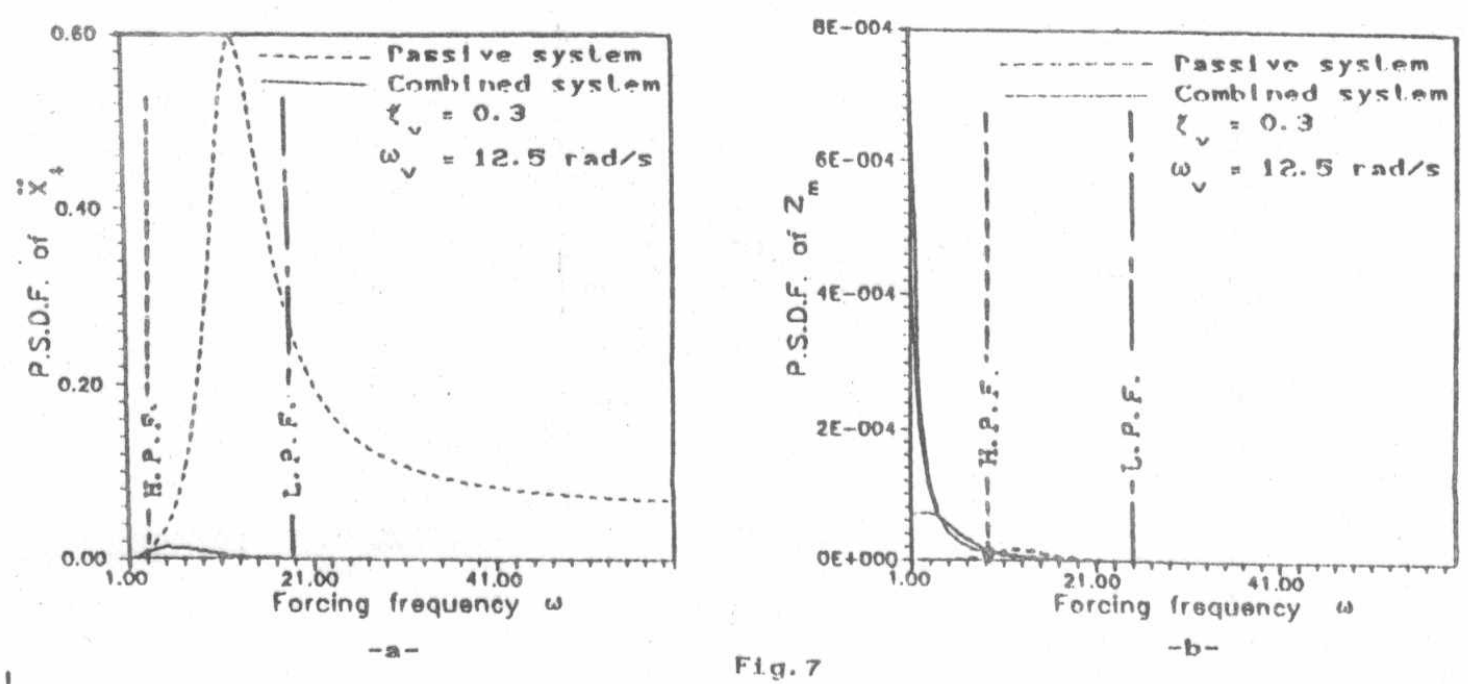
The first method to determine $\omega_{c}$ of a HPF is to point out the frequency at which the colncidence, that begins at the lower frequency limit, between the frequency response curves of $\ddot{x}$ of both the combined and the passive systems begins to vanish. Thereby, a considerable part from the eminent rrequency response of $Z$ can be omitted without any loss in the frequency response of $\dot{x}$. In this manner, the points of intersection between the dashed 11 nes and the horizontal axes in Figs. (z-a), $(3-a)$, and $(4-a)$ indicate that $\omega$ of a HPF can be approximately related to $\omega_{v}$ as rollows.

$$
\omega_{c} \cong 0.5 \omega_{v}
$$

Also, it is shown in Figs. (5-a), (6-a), and $(7-a)$ that a damping ratio $\xi_{v}$ greater than 0.1 violates, to a great extent, Eqn.(21). The above mentioned rigures indicate that at $\xi_{v}=0.3$, and whatever the value of $\omega_{v}, \omega$ becomes a constant value equals $3 \mathrm{rad} / \mathrm{s}$.

An alternative approach would be to use a varlable value of $\omega_{c}$ of a HPF. What is meant by variable $\omega_{c} 1 s$ to alter its value everytime the trade-or solution changes. For example, from the point of view of the frequency response, of $Z$, the black points in each of Figs. $(2-b),(3-b)$, and $(4-b)$ determine the correct positions of $\omega_{c}$ by which the maximum exploitation from the operation of a HPF can be taken. Since. whatever the I value of the desired trade-or
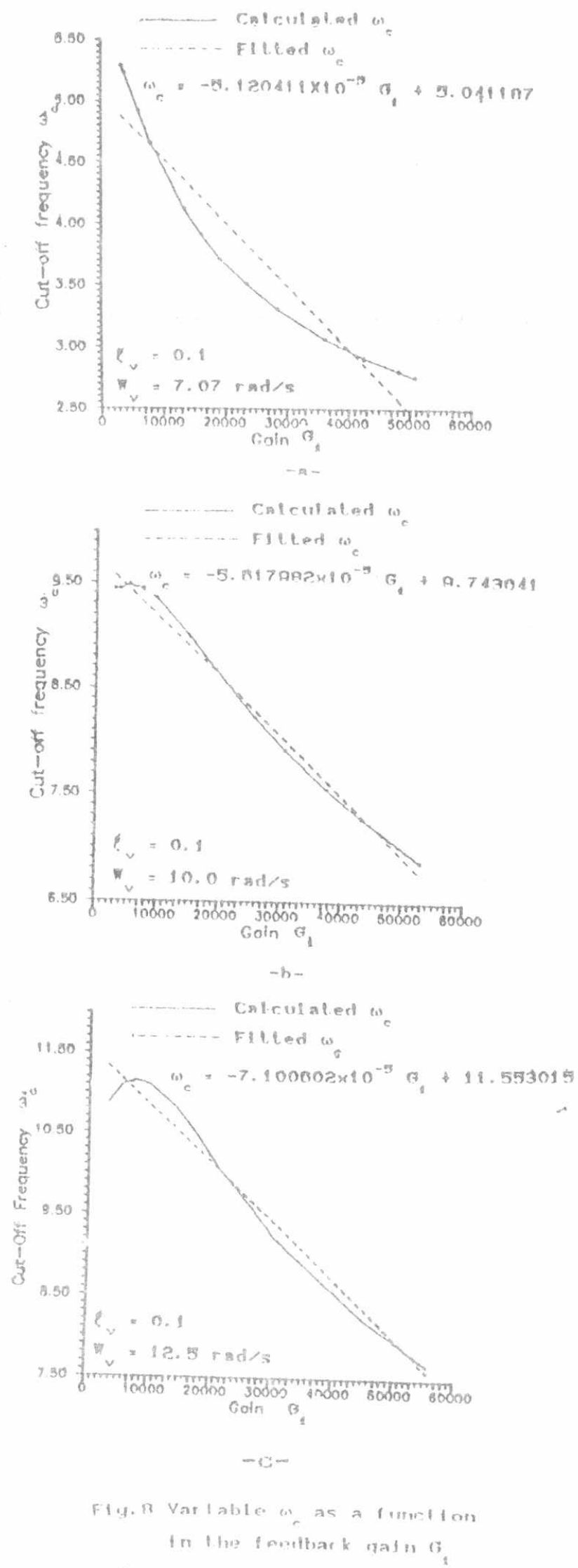


$$
14-! 6 \text { May } 1991 \text {, CA1120 }
$$

Isolution, values of $\xi_{v}$ and $\omega_{v}$ remain unchanged, the logic herel is to relate the variable $\omega_{c}$ to any of the optimum reedback gains, because they change every time the solution changes as shown in Table 1. A FORTRAN code is written by us to determine, with a considerable accuracy, the positions of the mentioned black polnts along the obtalned set of optimum trade-or solutions. The solid lines in Fig. 8 show the output of the FORTRAN code, while the dashed lines show a linearly fitted relation between $\omega_{c}$ and the feedback gain $G_{1}$. The maximum deviation between the fitted and the actual curves occurs at relatively small values of $\xi_{v}$ and $\omega_{v}$ as shown in Fig.(8-a). It is also obvious in Fig.(7-b) that at relatively large values of $\xi_{v}$ and $\omega_{v}$ all the frequency response curves of the combined system intersect that of the passive system at a unique point at $\omega=10 \mathrm{rad} / \mathrm{s}$. Therefore, there is no need for doing approximate relation or to use variable $\omega_{c}$, since $\omega_{c}$ can be taken as 10 $\mathrm{rad} / \mathrm{s}$. However, for the sake of exploring the performance of the modifled system with the two suggested ideal filters, the problem is solved at three different combinations of $\xi_{v}$ and $\omega_{v}$. The results are shown in Figs. 9, 10, and 11 .

\section{DISCUSSION OF RESULTS}

It should be stressed from the very beginning that. from practical point of view, the LPF seems to be better than The HPF. A LPF requires an actuator to operate at low exciting frequencles. Therefore. it reduces merely the cost of the system hardware. By the ald of Fig. $91 \mathrm{t}$ can be concluded that the LPF reaches 1 ts maximum potency at relatively small values of $\xi_{v}$ and $\omega$. While the maximum exploitation can be taken from the operation of a HPF at relatively 1 arge values of $\xi_{v}$ and $\omega_{v}$ as shown in Figs. 10 and 11 .

It is worth noting that the resulted sets of trade-off solutions by the use of a LPF in Fig. (9-a) seem to be very significant. since they are approximately horizontal, i.e., whatever the desired r.m.s. value of $Z$, the r.m.s. value of $x$ remains unchanged. Of course, such trend of solutions may meet the requirements of many actial applications. In addition, as shown in Fig. (9-b) a LPF with articulation to be given to the relative displacement $\left(\omega_{c}=15\right)$ achieves a considerable save in the r.m.s. actuated force rather than that when the articulation is given to the acceleration $\left(a_{i}=10\right)$. At relatively 1 arge values of $\xi_{v}$ and

\begin{tabular}{|c|c|c|c|c|c|c|c|}
\hline$o_{1}$ & $3_{1}$ & $6_{2}$ & $a_{3}$ & $u_{1}$ & $x_{i m}$ & z.s. & $z_{v m}$ \\
\hline $5 \times 10^{1}$ & -2236.0 & 428.0 & -682.0 & De. 0 & 3245 & .0248 &.$\infty 30$ \\
\hline $3 \times 10^{\prime}$ & -5477.0 & 300.0 & -1067.0 & 199.0 & 0207 & 0202 & .0050 \\
\hline $1 \times 10^{\circ}$ & -10000 . ! & 371.0 & -1440.0 & 315.0 & 0780 & 0175 & .009 \\
\hline $2 \times 10^{\circ}$ & -14142. & 352.0 & -1711.0 & 110.0 & 1. 2509 & 0101 & 0112 \\
\hline $4 \times 10^{\circ}$ & -200003 & 332.0 & -2032.0 & 534.0 & 1.0178 & 0147 & .0141 \\
\hline $6 \times 10^{\circ}$ & -244040 & 310.0 & -22480 & อ23. 0 & 1.0704 & 0140 & .0161 \\
\hline $\cos 0^{\circ}$ & $-3000 \times 0$ & 306.0 & -24500 & 720.0 & 2. 1000 & 0133 & 0483 \\
\hline $2 \times 10^{\circ}$ & $-4472: 0$ & 277.0 & -3031.0 & $\$ 90.0$ & 2. 0010 & 0120 & . 02000 \\
\hline $3 \times 10^{\circ}$ & -5477.0 & 202.0 & -33550 & 1141.0 & 3. 2042 & o113 & 0800 \\
\hline
\end{tabular}


1

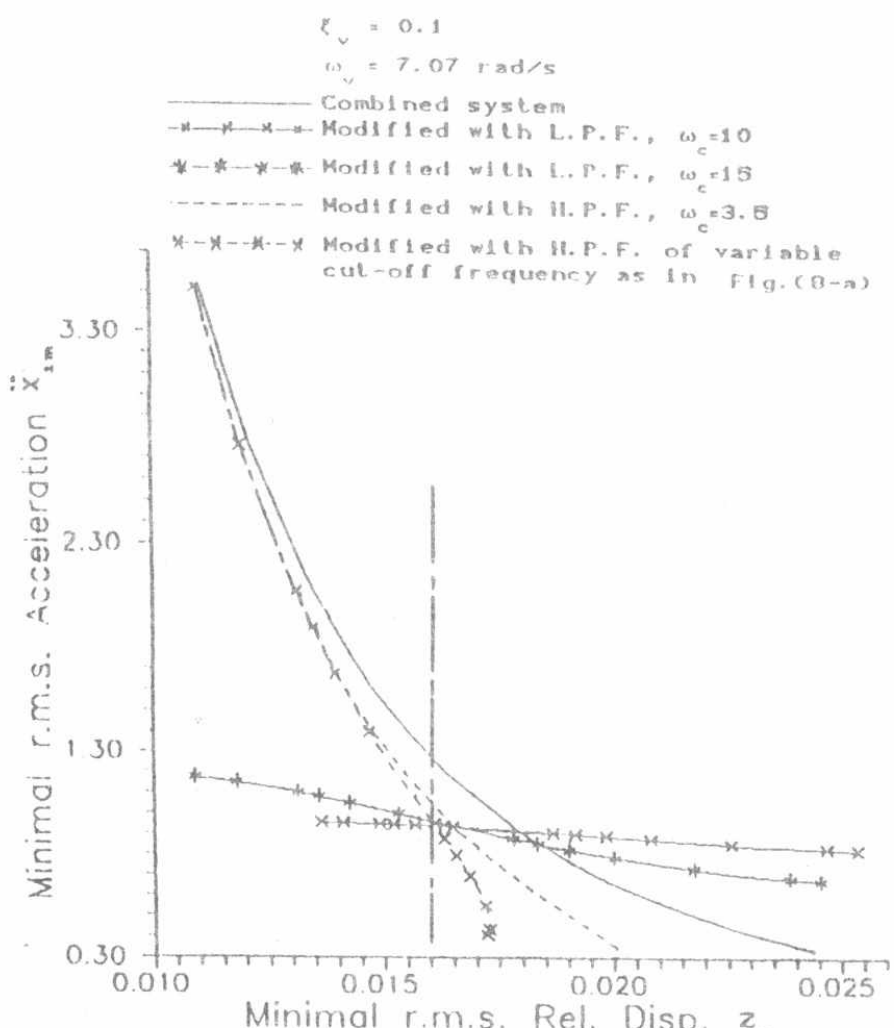

Fig. - - Compartson of trade-of solullos of vartous suggesled schemes for the operalion of the modfried system slong with the combined system

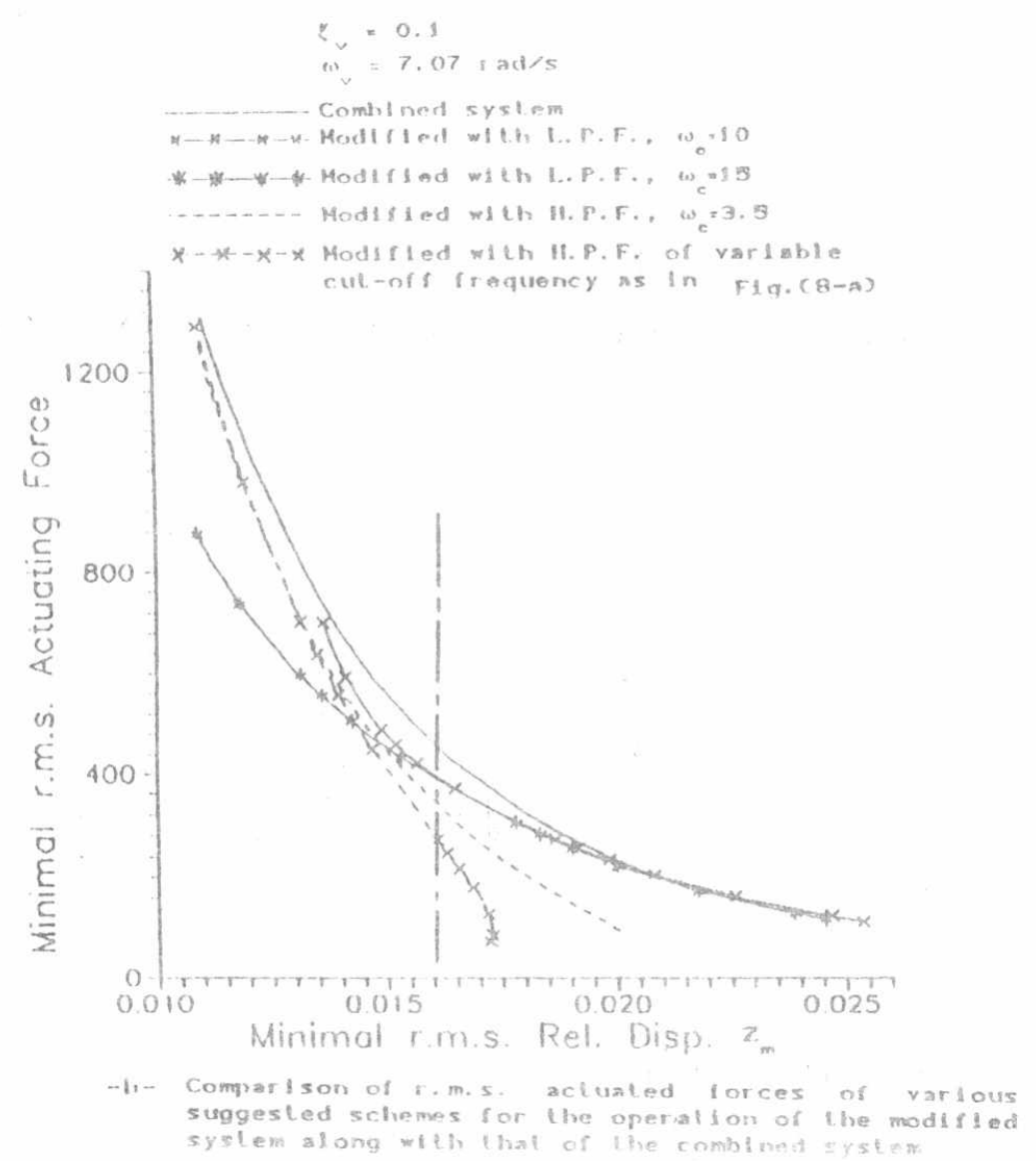




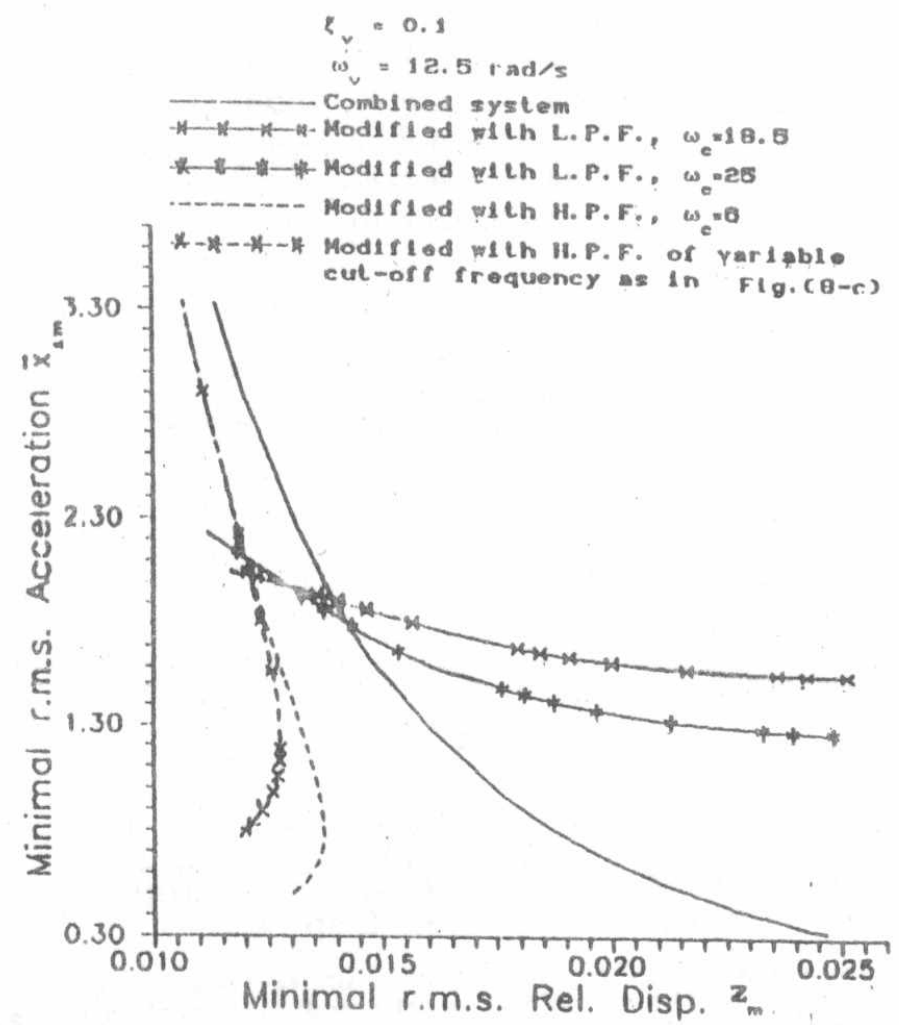

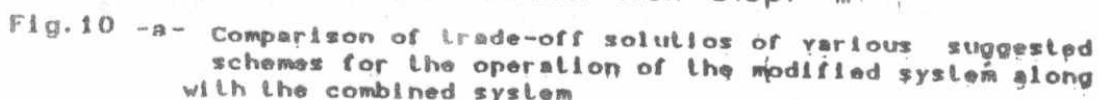
with the comblned system

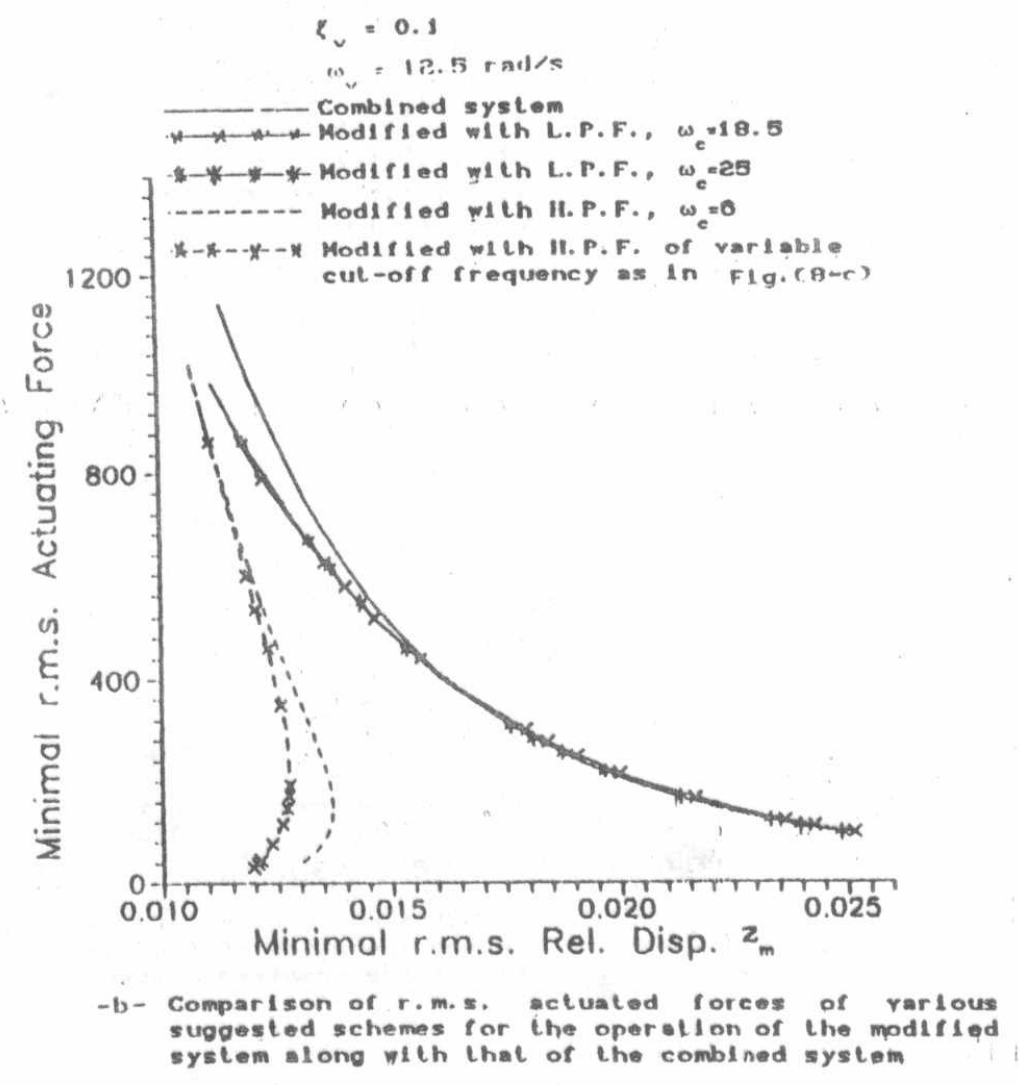




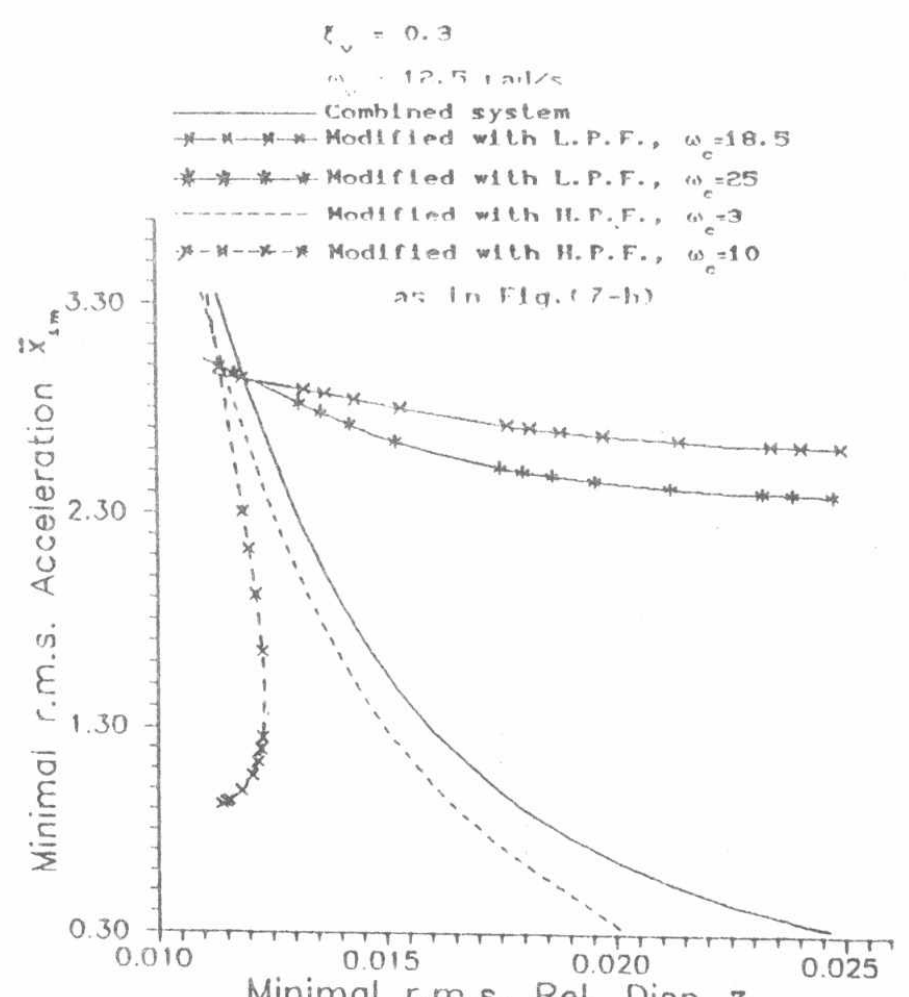
Fig.11 -a- Comparlson of trade-of solutios of vartous suggested
schemes for the operalion of the modiftad system along
whth the comblned system

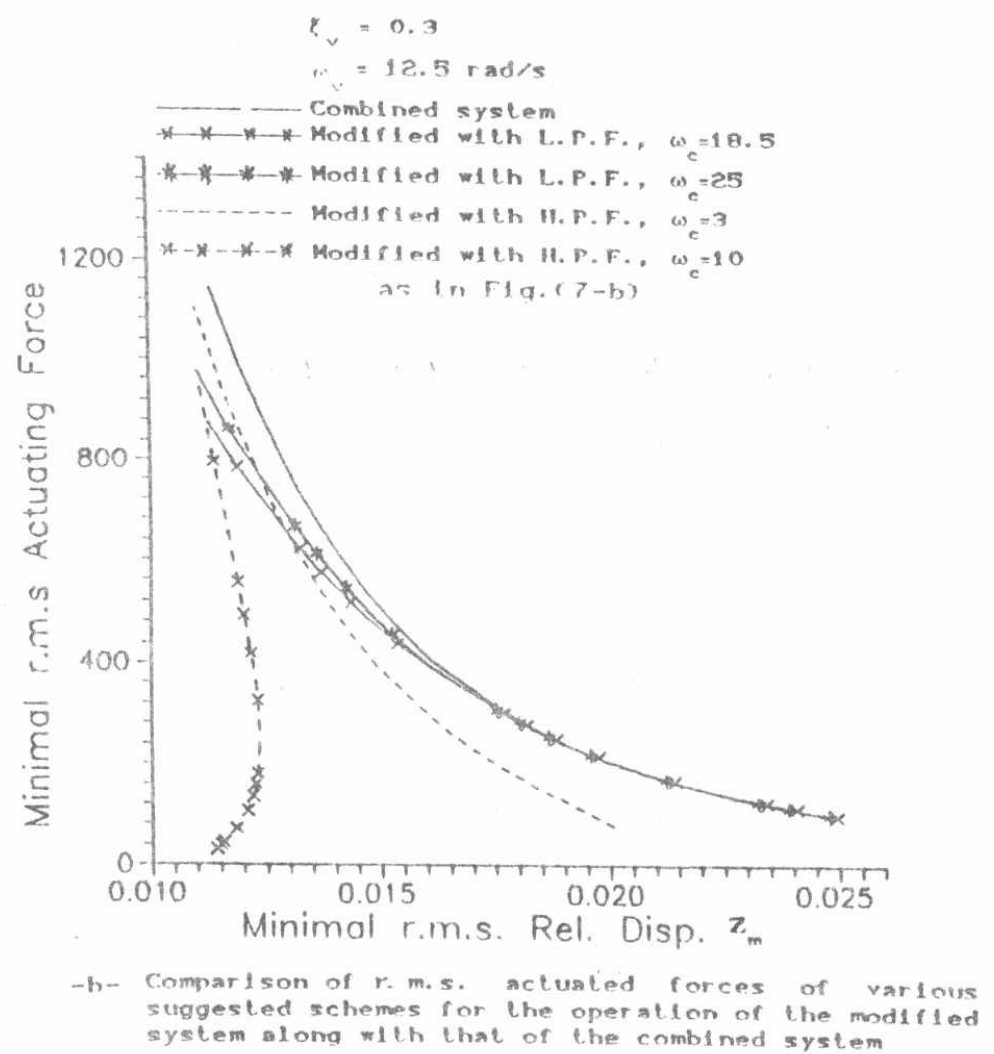


${ }^{1} \omega_{v}$ as shown in Fig.11 it is clear that no actual benefit can bel taken from the use of a LPF. This is in the time where the HPF with variable $\omega_{c}$ reaches its maximum potency. The of fered trend of trade-of solutions by use of a HPF with $\omega_{c}$ equals $10 \mathrm{rad} / \mathrm{s}$ In Fig. (11-a) seems to be very significant, since various values of $x_{1}$ can be taken with 11 thle change in the $r . m . s$ value of $z$ well as in the r.m.s. value of the actuated force as shown in Fig. $(11-b)$. Also, this trend of solutions is needed by many practical applications.

\section{CONCLUST ONS}

1 - The modified combined system is capable of providing a performance which can not be achieved by the combined system. In addition to 1 ts superior performance, it can provide a considerable save in the r.m.s. actuated force.

Z-Although the low 1 xed cost and the attainable rellabllity which can be achieved by implementing a LPF, the potency of such filter is not efrective except at low passive elements. In other words, a LPF loses quite its potency at relatively large passive elements.

3- The maximum explottation by 1 mplementing a HFF $1 \mathrm{n}$ the modifled system can be taken at relatively 1 arge values or the passive elements, but $1 \mathrm{t}$ remalns effective at elther low or moder ate values of these elements.

4-The ilxed passive elements can be properly selected and a LPF is 1 mplemented to achleve trade-off solutions in which the r.m.s. value of the accelerations seems to be approximately constant whatever the value of the relative displacement.

5- Also the rixed passive elements can be properly selected and a HPF can be used to obtain trade-off solutions in which the r.m.s. acceleration can be changed without efrective change in the r.m.s. relative displacement as well as the r.m.s. actuated rorce.

\section{REFERENCES}

1-El-Beheiry, E.M. . Hassan, S. A., and El-Shakey, S. A. "Pareto optimal design of a 11 near damped vibration absorber ", AME rourth conference, M. T.C., Kobry El-koba, (13-24) may 1990.

2-El-Sthakery, S. A. , Hassan, S. A., and El-Beheiry, E. M. "Opt1mum design of a combined vibration isolation system". Engg. Bull., Faculty of Engg., Aln Shams University, under refereeing.

3- Karnopp, D. C., Crosby, M. J., and Harwood, R. A. "Vibration control using semi-active force generators ", Trns. ASME, J. Engg Ind., $619-626(1974)$.

4- Krasnicki, E. J. " The experimental performance of an "ON-OFF" active damper. ", Shock \& Vib. Bul1. Vol. 51, Part 1. $125-131$ (1981)

5- Rakheja, S. and Sankar, S. "Vibration and shock 1 solation performance of a seml-active "On-Orf" damper ", Trns. ASME, J. Vib. Acoust. Stress Rell ab. Des., Vol. 107, 398-403(1985).

6- Alanoly, J. and Sankar, S. "A new concept in semi-active vibration isolation ", Trns. ASME, J. Mech. Trans. Aut. Des., Vol. 109, 242-247(1987).

7- Esmailzadeh, E. " Servoval ves controlled pneumatic suspension

", J. Mech. Engg. Sc., Vol. 21, No. 1, 7-18(1979) 
「 8- Guntur, R. R. and Sankar, S. "Fall-safe vibration control using active force generators " ". Trns. ASME, J. Vib. Acoust. Stress Rellab. Des., Vol. 105, 361-368(1983).

9- Hrovat, D. and Hubbard, M.," Optimum vehicle suspensions minimizing rms rattlespace, sprung mass acceleration, and jerk "2己8-236(1981) 10- Karnopp, D.C. and Trikha, A.K.," Comparative study of optimization techniques for shock and vibration isolation ", 11. ASME, J. Engg. Ind., $1128-1132(1969)$.

11- Kwakernaak, H. and Sivan, R. " Linear optimal control ", Wily Interscience, (197e).

12- Newl and, D. E. "An introduction to random vibration and spectral analysis", Sec. Edd., Longman Inc., New York (1984).

\section{APPENDIX $(A)$}

Since the excitation is a stationary random process, the performance 1 ndex in Eqn. (17) can be conveniently redefined by.

$$
\text { P.I. }=0.5 \int_{0}^{\infty}\left(z^{T} Q Z+u^{T} R u\right) d t
$$

Note that the matrix suffix is omitted for simplicity.

Moreover, the solution of the problem will be equivalent to that of a deterministic regulator problem in which [11].

$$
u(t)=-R^{-1} B^{T} P Y
$$

(A2)

And requires the solution of the following matrix Riccati equation to determine the matrix $\mathrm{P}$.

$$
A^{T} P+P A^{T}+C^{T} Q C-P B R^{-1} B^{T} P=0
$$

The main advantage of using the matrix riccati equation is that it provides a unfique solution which ensures the stability of the system. The solution of this matrix equation is feasible when the the pair $A$ and $B$ of the state space form (15) and (16) constitutes a completely controllable system such that:

$$
\operatorname{rank}\left[B, A B, A^{2} B, \ldots, A^{n-1} B\right]=n
$$
and the pair $A$ and $C$ ensure a completely observable system such
that :

$$
\operatorname{rank}\left[V^{T}, A^{T} V^{T},\left(A^{T}\right)^{2} V^{T}, \cdots, C\left(A^{T}\right)^{n-1} V^{T}\right]=n
$$

It is worth noting that the state form of Eqns.(7) and (8) satisfies (A4) and (A5).

\section{NOMENCLATURE}

[A]: matrix of state space form.

LAC. : accelerometer. 
[ [B] : matrix of state space form.

$C_{v}$ : classical passive damping

factor.

E[. ]: stands for variance.

F.G.: force generator.

$G_{1}, G_{2}, G_{3}$ : feedback gains

[P] : Riccati natrix

F.I. : performance index.

P.S.D.F.: power spectral density furction

[Q] : welghting matrix.

$Q_{1}, Q_{2}$ : weighting factors.

[R] : weightirig matrix.

$R$, weighting factor.

$[V]$ : output matrix

$x_{1}$ : displacement of the main mass

$X$ : Guassian random input.

$X_{v}$ : displacement of massless plate

$\dot{x}$

$X_{1 m}$ : minimal main mass acceleration

$Y_{3}, Y_{2}, Y_{3}$ : system state variables.

$Z$ : relative displacement, $x_{1}-x_{0}$.

$Z_{m}$ : minimal relative displacement

$Z_{v}$ : relative displacement, $x_{v}-x_{0}$.

[Z] : vector of controlled outputs.

$r_{0}$ : constant determines cperation

of a filtiation process

$m$ : primary mass.

$n$ : order of state space form

s : Laplace operator.

t : time instant.

$u_{c}$ : control law of a combined system

$u_{m}$ : control law of a modified system

$v_{0}$ : excitation constant.

$w(t):$ white noise excitations.

S(t): Dirac Delta Function.

$\xi_{v}$ : damping ratio of classical

passive system, $C_{v} \backslash 2 m_{1} \omega_{v}$.

$\tau$ : time instarit.

$\omega$ : forcing frequency.

$\omega_{c}$ : cut-off frequency.

$\omega_{u}$ : upper frequency $11 \mathrm{mit}$.

$\omega_{\mathrm{l}}$ : lower frequency $11 \mathrm{mt}$.

$\omega_{v}$ : natural frequency of

l passive system, $\sqrt{k_{v} / m_{i}}$. 